\title{
A efetividade da guarda compartilhada obrigatória como prevenção da alienação parental
}

\section{The effectiveness of the mandatory shared custody as prevention for the parental alienation}

\author{
Juliana Rielli Silveira D'Angeles Mendes ${ }^{1}$ \\ Ionete de Magalhães Souza ${ }^{2}$
}

\begin{abstract}
Resumo: O presente artigo tem como tema a efetividade da guarda compartilhada obrigatória como prevenção da alienação parental. A temática é relevante, tendo em vista a tardia formalização desses institutos no ordenamento brasileiro, bem como o alto número de litígios entre genitores acerca da guarda dos filhos, do que pode decorrer a alienação parental. Portanto, a pesquisa tem por escopo responder ao seguinte questionamento: a guarda compartilhada obrigatória é eficaz para prevenir a alienação parental? Objetiva-se, de forma geral analisar a efetividade da obrigatoriedade da guarda compartilhada como prevenção da alienação parental. Especificamente, aborda-se o tema a partir da noção histórica de família, com delineação do seu conceito; discorre-se sobre poder familiar; analisa-se a doutrina da proteção integral, que se desdobra nos princípios do melhor interesse da criança, da prioridade, do cuidado e da afetividade; examina-se a dissolução das entidades familiares; especificam-se as modalidades de guarda existentes no ordenamento; examina-se a instituição da obrigatoriedade da guarda compartilhada; discorre-se sobre a alienação parental, nos moldes de Lei no 12.318/2010. Realiza-se uma pesquisa qualitativa, exploratória, bibliográfica, documental, histórica e jurisprudencial. Ainda, utiliza-se do método de abordagem dedutivo e do método de procedimento monográfico. A guarda compartilhada obrigatória enseja o diálogo e o respeito entre os genitores, porquanto fomenta o acompanhamento multiprofissional, de forma que os problemas advindos do rompimento do vínculo conjugal não afetem o relacionamento com os filhos. Portanto, conclui-se que a guarda compartilhada obrigatória é instrumento eficaz de prevenção da alienação parental.
\end{abstract}

Palavras-chave: Alienação Parental. Divórcio. Guarda Compartilhada Obrigatória. Princípio do Melhor Interesse da Criança. Direito das Famílias.

\footnotetext{
${ }_{1}^{1}$ Pós graduanda lato sensu em Direito e Processo Previdenciário pelo Centro Universitário UniDomBosco. Graduada em Direito pela Universidade Estadual de Montes Claros Unimontes.

2 Doutora em Direito - Universidad del Museo Social Argentino (2013). Mestre em Direito Universidade Federal de Santa Catarina - UFSC (2001). Pós-Graduada lato sensu e Graduada em Direito pela Universidade Estadual de Montes Claros - Unimontes. Professora de Graduação e Pós-Graduação da Universidade Estadual de Montes Claros Unimontes. Advogada.
} 


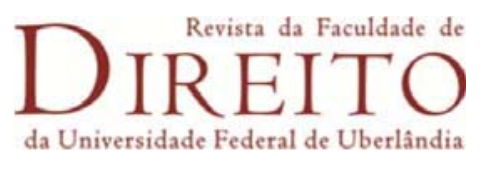

\begin{abstract}
The present article's theme is the effectiveness of the mandatory shared custody as prevention for the parental alienation. The theme is relevant in view of the late formalization of these themes in the Brazilian order as well as the high number of disputes between parents about the custody of children, when parental alienation can take place. Therefore, the research intends to answer the following question: is the mandatory shared custody effective to prevent parent alienation? The objective is, in general, to analyze the effectiveness of mandatory shared custody as prevention of parental alienation. Specifically, it traces the historical notion of the family, outlining its concept; talks about family power; analyzes the doctrine of integral protection which unfolds in the principles of the best interest of the child, of priority, care and affection; examines the families dissolution, specifies the modalities of custody existing in the order, examines the institution of mandatory shared custody; discusses parental alienation, in accordance with Law no. 12.318/2010. It was performed a qualitative, exploratory, bibliographic, documental, historical and jurisprudential research. Yet, the method of deductive approach and the standard procedural monographic method were used. The mandatory shared custody encourages dialogue and respect between parents, because it promotes multiprofessional follow-up, so that the problems arising from the divorce don't affect the relationship with the children, protecting the best interest of the child and the fundamental right of coexistence. Therefore, it is concluded that the mandatory shared custody is an effective instrument for preventing parental alienation.
\end{abstract}

Keywords: Parental Alienation. Divorce. Mandatory Shared Custody. The Best Interests Of The Child. Family Law.

\title{
1. Introdução
}

O presente artigo tem como tema a efetividade da guarda compartilhada obrigatória como prevenção da alienação parental. A temática é relevante, visto o crescimento do número de divórcios no país, que enseja discussões acerca de suas consequências na convivência entre os membros da família, porquanto, comumente, há um desencadear de impasses e choques de interesses, que podem acarretar disfunções como a alienação parental, violando o melhor interesse da criança e do adolescente.

O tema é atual, haja vista a tardia formalização da alienação parental e da obrigatoriedade da guarda compartilhada no ordenamento brasileiro. Portanto, a pesquisa tem por escopo responder ao seguinte questionamento: a guarda compartilhada obrigatória é eficaz para prevenir a alienação parental? 
O objetivo geral do trabalho é verificar se a guarda compartilhada obrigatória se constitui eficazmente como prevenção da alienação parental. De maneira específica, traça-se a noção histórica de família, delineando seu conceito; discorre-se sobre poder familiar; analisa-se a doutrina da proteção integral, que se desdobra nos princípios do melhor interesse da criança, da prioridade, do cuidado e da afetividade; examina-se a dissolução das entidades familiares; especificam-se as modalidades de guarda existentes no ordenamento; examina-se a obrigatoriedade da guarda compartilhada; discorre-se sobre a alienação parental, nos moldes de Lei no 12.318 de 26 de agosto de 2010 (Lei da Alienação Parental), verificando a efetividade da guarda compartilhada obrigatória como prevenção da alienação parental.

Essa análise se realiza mediante pesquisa qualitativa, exploratória, bibliográfica, documental, histórica e jurisprudencial, utilizando-se do método de abordagem dedutivo e do método de procedimento monográfico.

\section{Noções históricas e conceito de família}

A origem da família é ponto controvertido ao longo da história, haja vista que não nasce como fato jurídico; mas como construção social, demonstrando variações de acordo com cada sociedade (ENGELS, 1984). Nessa toada, o estado primitivo das civilizações que habitavam o continente americano, asiático e africano revela a prática de poligamia e poliandria, com predominância do matriarcado, pois os filhos ficavam junto à mãe, que os alimentava e educava (ENGELS, 1984).

De forma diversa, no curso das primeiras civilizações assíria, hindu, egípcia, grega e romana, verifica-se que: "o conceito de família foi de uma entidade ampla e hierarquizada [...]" (VENOSA, 2017, p. 19). Ademais, a entidade familiar se fundava na religião, independentemente de laços de parentesco. Já o poder familiar se concentrava no chefe da família (pater famílias), que representava os indivíduos sob seu domínio, denotando a assimetria entre o pater famílias e a mulher in manus, bem como o 


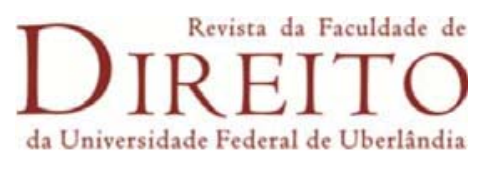

patriarcalismo existente desde a antiguidade, o que vincula a concepção de família às coisas, ao patrimônio e à totalidade dos escravos pertencentes a um senhor (MIRANDA, 2001).

Posteriormente, no início da idade contemporânea, a Carta dos Direitos do Homem e do Cidadão de 1789, fruto da Revolução Francesa já trazia em seu bojo a concepção de família atrelada ao afeto e com igualdade de poderes entre os genitores (FRANÇA, 1789). Entretanto, a entidade familiar ainda era composta por pais com inúmeros filhos, preocupados com a subsistência coletiva, de modo que as crianças já se inseriam no mundo adulto e laboral, pois a família era um fim em si mesma, na medida em que cumpria uma função social (ARIÈS, 1986).

Com o advento da Revolução Industrial, a concepção de família sofre modificações, fomentadas, sobretudo, pela inserção das crianças no âmbito educacional, de modo que: "Os pais não se contentavam mais em pôr filhos no mundo [...] A moral da época lhes impunha proporcionar a todos os filhos [...] uma preparação para a vida" (ARIÈS, 1986, p. 277).

Além da educação, o trabalho nas fábricas e a vida familiar privada reduziram a frequência das interações sociais no âmbito público. Logo, resgata-se a concepção do direito romano de família como instituição fechada, com divisão social em classes e uniformidade entre seus membros, destacando-se a figura do chefe da unidade familiar (MIRANDA, 2001).

No âmbito nacional, com o advento da Constituição da República Federativa do Brasil (CF/88), a concepção de família se afina com a prevista na Carta dos Direitos do Homem e do Cidadão de 1789, sendo considerada base da sociedade, com proteção do Estado (BRASIL, 1988). Conceitualmente, ainda perdura a diversidade de acepcõos da família. Nesse viés:

Ora significa o conjunto das pessoas que descendem de tronco ancestral comum [...] ora o conjunto de pessoas ligadas a alguém, ou a um casal, pelos laços de consangüinidade ou de parentesco civil; ora o conjunto das mesmas pessoas, mais os afins apontados por lei; ora o marido e a mulher, descendentes e adotados; ora [...] 
marido, mulher e parentes sucessíveis de um e de outra (MIRANDA, 2001, p. 59).

Predomina, contudo, o conceito de família como unidade social. Nesse ponto, a Convenção Internacional Sobre os Direitos da Criança, internalizada pelo Decreto n 99.710 de 21 de novembro de 1990 (Convenção Sobre os Direitos da Criança), conceitua família como: "grupo fundamental da sociedade e meio natural para o crescimento e bem-estar de todos os seus membros e, em particular, as crianças" (BRASIL, 1990).

Consequentemente, e tendo por princípio basilar a afeição entre seus membros, identificam-se diversos arranjos familiares, como a união homoafetiva; família recomposta, constituída por filhos de vários casamentos convivendo com pais recasados; arranjo monoparental que, segundo o art. $226, \S 4^{\circ}$ da $\mathrm{CF} / 88$, consubstancia-se na: "comunidade formada por qualquer dos pais e seus descendentes" (BRASIL, 1988).

Destarte, verifica-se a maleabilidade e fluidez do conceito de família, que não mais comporta formações estáticas, havendo uma primazia da proteção dos infantes, no exercício do poder familiar.

\section{Poder Familiar}

A família enseja o surgimento de direitos e deveres entre seus membros. Na convivência com os filhos, desenvolve-se para os pais a figura do "poder familiar", originado do pátria potestas do direito romano, razão pela qual era chamado de pátrio poder (MIRANDA, 2001).

No Brasil, construiu-se ao longo do século XX, na legislação, a possibilidade de atuação materna no âmbito do pátrio poder. Nesse sentido:

[...] o Código Civil Brasileiro de 1916, em seu texto original, já havia temperado a exclusividade da atuação paterna, dedicando um restrito espaço à mãe. [...] $\mathrm{O}$ alcance da igualdade entre os cônjuges, introduzido pelo Estatuto da Mulher Casada (Lei n. 4.121/62), aumentou a esfera de atuação materna, e, na atualidade, o poder familiar ou parental é exercido em igualdade de condições tanto pela mãe quanto pelo pai (RAMOS, 2016, p. 38). 
Além disso, a CF/88 prevê o tratamento isonômico dos filhos e a equiparação dos direitos e deveres dos cônjuges. No âmbito infraconstitucional, com o advento do CC/02, supera-se a concepção do pátrio poder, como poder-sujeição, adotando-se o poder familiar como visão de família equânime, participativa e democrática (BRASIL, 2002). Portanto, a relação da autoridade parental: "não é mais entre um sujeito e um objeto, mas uma correlação de pessoas, onde não é possível conceber um sujeito subjugado a outro" (PERLINGIERI, 1997, p. 258).

Importante destacar que, a essa concepção, adequa-se a expressão "autoridade parental", que seria adotada pelo Estatuto das Famílias, cujo projeto foi arquivado pelo Senado em 2018 (PLS 470/2013).

Quanto às características, o poder familiar é múnus público, sendo indisponível, indivisível, imprescritível; intransferível e irrenunciável, já que: "As obrigações que dele fluem são personalíssimas. Como os pais não podem renunciar aos filhos, os encargos que derivam da paternidade também não podem ser transferidos ou alienados" (DIAS, 2011, p. 414).

Assim, enquanto os filhos não tenham atingido a capacidade civil plena, estarão sujeitos ao poder familiar, que não se trata de um poder em si, pois impõe aos pais deveres, de forma ampla, da defesa dos interesses dos filhos, tendo-os em sua companhia e guarda, conforme art. 1.634 do CC/02 (BRASIL, 2002).

Por outro lado, o desvio do comportamento esperado dos genitores frente ao exercício do poder familiar pode acarretar a sua suspensão, medida temporária, ou a perda, medida definitiva, consoante hipóteses previstas nos arts. 1.635 e 1.637 do CC/02, respectivamente, constando, dentre elas, a prática de alienação parental (BRASIL, 2002). Nesse ponto, insta salientar que restou superada a visão patrimonialista do Código Civil anterior, de modo que a falta ou carência de recursos materiais não constitui motivo suficiente para perda ou a suspensão do poder familiar, nos termos do art. 23 do Estatuto da Criança e do Adolescente (ECA) (BRASIL, 1990). 
Portanto, verifica-se que o poder familiar deve ser exercido com responsabilidade, pois influencia diretamente a formação do filho, justificando a intervenção do Estado, em caso de violação a esse dever, em consonância com a doutrina da proteção integral, que se analisa a seguir.

\section{Doutrina da proteção integral: melhor interesse da criança, prioridade, cuidado e afeto.}

A doutrina da proteção integral se desenvolveu a partir da previsão do art. 227, $\S 3^{\circ}$ da CF/88, que utilizou o termo "proteção especial" da criança, do adolescente e do jovem, inovando em relação às constituições anteriores (BRASIL, 1988). Do mesmo modo, o art. $3^{\circ}$ do ECA instituiu a proteção integral da criança e do adolescente, de forma a preconizar a tutela jurídica de todas as necessidades do ser humano, propiciando o pleno desenvolvimento da personalidade (NUCCI, 2014).

Consequentemente, a doutrina da proteção integral possui viés principiológico com aplicabilidade em todo o ordenamento. Em seus aspectos conceituais, os princípios "não contêm um mandamento definitivo, mas apenas prima facie [...] representam razões que podem ser afastadas por razões antagônicas" (ALEXY, 2008, p. 103).

Logo, denota-se que: "princípios exigem que algo seja realizado na maior medida possível dentro das possibilidades jurídicas e fáticas existentes" (ALEXY, 2008, p. 103). Especificadamente, o princípio da proteção integral decorre da dignidade da pessoa humana, prevista no art. $1^{\circ}$, III da CF/88 como fundamento da República Federativa do Brasil (BRASIL, 1988).

Para Kant (2007, p. 77), a dignidade é uma característica intrínseca ao ser humano, advinda da sua racionalidade e de suas motivações de vida, de forma que: "No reino dos fins tudo tem ou um preço ou uma dignidade. Quando uma coisa tem um preço, pode-se pôr em vez dela qualquer outra como equivalente; mas quando uma coisa está acima de todo o preço [...] 
então tem ela dignidade" (KANT, 2007, p. 77). Nessa toada, a natureza racional e a dignidade distinguem o ser humano dos objetos e dos seres irracionais. Os seres racionais, por sua vez, são chamados de pessoas, porque são um fim em si mesmos, não podendo ser empregados como meio (KANT, 2007).

A partir dessa linha de pensamento, que culminou na reaproximação entre ética e direito, denota-se uma ordem voltada ao ser humano, com garantia de seu pleno desenvolvimento, constituindo-se a dignidade como "núcleo básico e informador de todo o ordenamento jurídico [...] parâmetro de valoração a orientar a interpretação e compreensão do sistema constitucional" (PIOVESAN, 2013, p. 86-87).

Logo, a proteção integral se projeta internamente e no âmbito internacional, por meio de tratados como a Declaração Universal dos Direitos da Criança; Pacto de San José da Costa Rica e Convenção sobre os Direitos da Criança. Assim, crianças e adolescentes possuem: "uma hiperdignificação da sua vida, superando quaisquer obstáculos [...] para regrar ou limitar o gozo de bens e direitos [...]” (NUCCI, 2014, p. 24).

Noutro giro, a doutrina da proteção integral reconhece crianças e adolescentes como sujeitos de direitos. Rompe-se, portanto, com a doutrina menorista, sobretudo com o advento do ECA, que superou o tratamento precário dado aos infantes, levando em consideração os seus interesses e necessidades (BRASIL, 1990).

Dessa conjuntura decorre o princípio do melhor interesse da criança (best interest of the child) ou do interesse superior, que impõe a preservação daqueles que se encontram em situação de fragilidade, tendo a criança e o adolescente o direito fundamental de se desenvolver sob as melhores garantias morais e materiais. Por conseguinte, estimula-se uma atitude positiva do Estado, que passa a intervir no seio familiar para garantir o melhor interesse da criança (PIOVESAN, 2013). Nesse sentido: 
Sempre que os direitos da criança e do adolescente forem violados ou mesmo estiverem sob ameaça de violação normativa ou principiológica, faz-se necessária [...] a pronta intervenção estatal [...] com a garantia de sua liberdade positiva. [...] garantindo [...] que o ambiente familiar seja o espaço profícuo para [...] desenvolvimento da personalidade (FACHIN, 2015, p. 167).

Lado outro, deriva da proteção integral o princípio da prioridade que:

[...] impõe e vincula iniciativas legislativas e administrativas dos poderes da República, de forma a atender, promover, defender ou, no mínimo, considerar a prioridade absoluta dos direitos fundamentais de crianças e adolescentes (RIBEIRO; SANTOS; SOUZA, 2012, p. 31).

Nessa linha, a Convenção Sobre os Direitos da Criança demonstra o acolhimento: "da concep̧̧ão do desenvolvimento integral da criança, reconhecendo-a como verdadeiro sujeito de direito, a exigir proteção especial e absoluta prioridade" (PIOVESAN, 2013, p. 276). Referidas disposições não violam o princípio da igualdade, pois buscam a realização da isonomia, conceituada por Barbosa (1999, p. 25) como: “[...] quinhoar desigualmente aos desiguais, na medida em que se desigualam".

Posto isto, verifica-se que a doutrina da proteção integral perpassa também pelo princípio do cuidado. Para Heidegger (1986), cuidado significa cura e antecede toda situação e atitude do ser humano. Por sua vez, Boff (1999) leciona que o cuidado advém da essência humana; contudo, deve se harmonizar com o trabalho, pois são conceitos que se compõem; mas que foram afastados nos últimos séculos. Nesse viés:

[...] a ditadura do modo-de-ser-trabalho-dominação masculinizou as relações, abriu espaço para o antropocentrismo, o androcentrismo, o patriarcalismo e o machismo. [...] expressões patológicas do masculino desconectado do feminino [...] $\mathrm{O}$ cuidado foi difamado como feminilização das práticas humanas, como [...] obstáculo à eficácia (BOFF, 1999, p. 48-49).

Logo, a falta de cuidado leva a disfunções sociais, sobretudo no seio familiar, de modo que: "Sem o cuidado não há atmosfera que propicie o florescimento daquilo que verdadeiramente humaniza: o sentimento profundo, a vontade de partilha e a busca do amor" (BOFF, 1999, p. 58). 
Vislumbrando essa situação, a CF/88 resgatou o princípio do cuidado, que se projeta na legislação ordinária, por meio do direito a alimentos e na proteção da pessoa dos filhos no CC/02. Da mesma forma, o ECA estabelece prioridade absoluta das crianças e adolescentes em receber socorro pelos pais, pela sociedade ou pelo Poder Público. Além disso, a Convenção Sobre os Direitos da Criança prevê, nos arts. $3^{\circ}$ e 18, o cuidado como dever do Estado e da família (BRASIL, 1990).

No âmbito jurisprudencial, há precedentes das Cortes Superiores de reconhecimento de danos morais ocasionados por abandono afetivo, com fundamento na violação do dever de cuidado (PEREIRA, 2018). Da mesma forma, o cuidado se associa ao princípio da afetividade e possibilita a construção do parentesco com base no afeto, em razão de que a jurisprudência pátria reconhece a coexistência entre vínculos biológicos e socioafetivos (DIAS, 2011). Por conseguinte, geram-se influxos na nova concepção familiar, pois: "Ao enfatizar o afeto, a família passou a ser uma entidade plural, calcada na dignidade da pessoa humana” (PEREIRA, 2018, p. 69).

Dessarte, verifica-se que o laço de afeto deriva da convivência e se constitui como direito de crianças e adolescentes, devendo ser protegido, em razão do melhor interesse superior, do que decorre a importância da convivência dos filhos com os pais, mesmo após a dissolução da entidade familiar.

\section{Dissolução das entidades familiares}

Uma vez reconhecido o afeto como princípio basilar das relações familiares, a união entre pessoas e sua proteção não visa mais a fins patrimoniais; mas à dignidade da pessoa humana, refletindo a despatrimonialização do direito de família, que significa: "[...] que o direito de família passe a girar [...] em torno de fenômenos humanos, ligados à 
esfera afetiva, espiritual e psicológica [...] e não de facetas de natureza predominantemente patrimonial. (RAMOS, 2016, p. 77).

Desse modo, o casamento e a união estável pressupõem a comunhão plena de vida - cláusula aberta, englobante da convivência, afeto, direitos e deveres - que transforma a família em meio de realização e da felicidade de seus membros, não se justificando a manutenção do vínculo conjugal como um fim em si mesmo. Logo, facilita-se a sua dissolução, que pode ter como causa: "[...] uma paulatina, intermitente ou sucessiva infração dos deveres que resultam do matrimônio e participa da própria contingência humana" (CAHALI, 2005, p. 25).

Juridicamente, a dissolução do casamento e da sociedade conjugal é prevista na Lei $n^{\circ}$ 6.515, de 26 de dezembro de 1977 (Lei do Divórcio). No âmbito constitucional, a EC 66/2010 alterou o art. 226, $\S 6^{\circ}$ da CF/88, suprimindo o requisito de prévia separação judicial por mais de um ano ou de comprovada separação de fato por mais de dois anos. Prima-se, portanto, pela liberdade e independência do indivíduo em administrar suas relações, bastando a autonomia da vontade para dissolver o casamento.

Essa modificação denotou um avanço em relação aos demais países, pois: “[...] Alemanha, Portugal, Espanha, Japão, França, entre outros [...] não possuem, da vertente constitucional positiva, um comando normativo tão pujante, liberal e inovador" (BULOS, 2014, p. 1.620). A partir dessas modificações, há um crescimento exponencial no número de divórcios, conforme dados do Instituto Brasileiro de Geografia e Estatística (IBGE), que só passou a mensurá-los em 1984, sete anos após a edição da Lei do Divórcio, ocasião em que se contabilizaram 63.698 separações judiciais e 31.685 divórcios no âmbito nacional (IBGE, 1984).

Mais recentemente, o número de divórcios continua em ascensão, pois, em 2018, a pesquisa Estatística do Registro Civil apurou 385.246 divórcios concedidos judicialmente em primeira instância ou por escrituras extrajudiciais, o que representa um incremento de $3,2 \%$ em relação ao total 
contabilizado em 2017 (IBGE, 2018). Quanto à relação de divórcio por tipo de arranjo familiar, observou-se que a maior proporção das dissoluções ocorreu entre as famílias constituídas somente com filhos menores de idade, com o aumento de 5,6\% entre 2008 e 2018, atingindo o patamar de 46,6\% do número de divórcios em 2018 (IBGE, 2018).

Nessa toada, é inolvidável que a dissolução das entidades familiares, em regra, está calcada em desgaste do relacionamento dos consortes, sendo um momento delicado, sobretudo considerando os altos índices de divórcio em arranjos familiares compostos por crianças e adolescentes. Portanto, destaca-se que os filhos são fruto do matrimônio e dele não se dissociam, tendo em vista que possuem o direito fundamental de convivência com os pais, podendo ser o instituto da guarda uma forma de garanti-lo, conforme se analisa a seguir.

\section{Modalidades de guarda no ordenamento brasileiro}

Decorre do poder familiar o dever de proteção dos infantes, que compreende a sua criação e não se limita à concessão de recursos materiais, abrangendo também, na linha dos princípios da afetividade e do cuidado, o direito à convivência, que é: "relação afetiva diuturna e duradoura entretecida pelas pessoas que compõem o grupo familiar, em virtude de laços de parentesco ou não, no ambiente comum" (LÔBO, 2011, p. 74).

Esse direito, inclusive, já era vislumbrado na Alemanha, na metade do século XX. Nesse sentido:

\footnotetext{
[...] a Alemanha Ocidental, através da Lei Matrimonial de 20.02.1946 [...] estabeleceu dificuldades para o divórcio por perturbação objetiva da sociedade conjugal representada pela cessação da convivência familiar, mandando que se levasse em conta [...] o bem-estar dos filhos menores (CAHALI, 2005, p. 34).
}

No Brasil, o art. 227 da CF/88 estatui que a convivência familiar e comunitária é direito fundamental de crianças, adolescentes e jovens, não podendo restar prejudicado, mesmo com o divórcio ou separação dos genitores que antes coabitavam no mesmo local (BRASIL, 1988). 
Nessa linha, dispõe o art. 9.3 da Convenção Sobre os Direitos da Criança que o infante tem direito de: "manter regularmente relações pessoais e contato direto com ambos, a menos que isso seja contrário ao interesse maior da criança” (BRASIL, 1990). Ademais, esse direito é recíproco, nos termos do art. 1.632 do CC/02: “A separação judicial, o divórcio e a dissolução da união estável não alteram as relações entre pais e filhos senão quanto ao direito, que aos primeiros cabe, de terem em sua companhia os segundos" (BRASIL, 2002).

Diferentemente da convivência, a guarda se refere à tutela dos infantes e à gestão da vida da prole, atuando como meio de exercício do poder familiar, cujo conteúdo perfaz, nos termos do art. 33 do ECA: “[...] a prestação de assistência material, moral e educacional à criança ou adolescente, conferindo a seu detentor o direito de opor-se a terceiros, inclusive aos pais" (BRASIL, 1990).

De forma específica, a guarda natural decorre do reconhecimento do filho, na forma do art. 1.612 do CC/02. Já a guarda comum ou conjunta é desempenhada pelo modelo de família constituída pelo casamento ou união estável (BRASIL, 2002). Com a dissolução da entidade familiar, outras modalidades de guarda são previstas pelo ordenamento.

Até a promulgação da Lei da Guarda Compartilhada Obrigatória, deferia-se, em regra, a guarda unilateral, também chamada de guarda única, exclusiva ou uniparental, que, consoante art. 1.583, $\S 1^{\circ}$ do CC/02, é: "a atribuída a um só dos genitores ou a alguém que o substitua" (BRASIL, 2002). Nessa modalidade, o infante fica em residência fixa, com um dos pais, que exercerá a gestão da sua vida. Do outro genitor, a criança apenas recebe visitas, que são determinadas ou acordadas judicialmente, conforme art. 15 da Lei do Divórcio (BRASIL, 1977).

Consequentemente, ainda que ressalvado o exercício do poder familiar pelo não detentor da guarda, por meio da fiscalização da manutenção e 
educação da criança, este resta prejudicado na convivência, porquanto seu surgimento como visita o afasta da responsabilidade familiar (DIAS, 2011).

Logo, esses encontros podem se tornar mais esparsos, e o infante, gradativamente, mais distante de um genitor, sobejando lesado seu direito de conviver com ambos (DIAS, 2011). Ato contínuo, referida modalidade é alvo de críticas, pois afronta princípios constitucionais de isonomia e do melhor interesse da criança.

De forma diversa, a guarda compartilhada, também chamada de guarda conjunta, é definida pela parte final do $\S 1^{\circ}$ do art. 1.583 do CC/02 como: "responsabilização conjunta e o exercício de direitos e deveres do pai e da mãe que não vivam sob o mesmo teto, concernentes ao poder familiar dos filhos comuns" (BRASIL, 2002). Nessa toada, compartilhar significa arcar juntamente e liga-se à família, pois envolve a vivência, o convívio e a partilha entre os indivíduos. Portanto, guarda compartilhada é um prolongamento desses princípios de participação e afeto, mesmo com o fim da união conjugal, sendo, a partir de 2014, obrigatório seu deferimento (VENOSA, 2017).

Há, ainda, um modelo derivado da guarda compartilhada denominado de aninhamento, em que: "O filho permanece na residência e são os genitores que se revezam, mudando-se periodicamente cada um deles para a casa em que o filho permanece" (DIAS, 2011, p. 433). Por outro lado, há críticas à guarda compartilhada por se assemelhar à modalidade alternada; contudo, são espécies que não se confundem, pois na guarda alternada não há residência fixa. Assim, os filhos ficam por determinado período de tempo com cada genitor, de modo que: "Confere-se de forma exclusiva o poder parental por períodos preestabelecidos de tempo, [...] entre as casas dos genitores" (DIAS, 2011, p. 435).

De fato, esse arranjo gera a inconstância da permanência no lar por parte do filho, o que repercute na ausência de sustentação para seu amadurecimento, razão pela qual é pouco utilizado (LÔBO, 2011). 
Diferentemente, a guarda compartilhada permite a fixação de domicílio para a criança, já que enseja a partilha de direitos e deveres concernentes ao poder familiar, o que nem sempre implica a detenção da guarda física (DIAS, 2011).

Por fim, destaca-se que as modalidades de guarda citadas não esgotam as subdivisões existentes, entretanto, são as mais conhecidas e que merecem, no momento, maior atenção.

\subsection{Obrigatoriedade da guarda compartilhada}

$\mathrm{Na}$ definição de guarda compartilhada, há dois conceitos: a guarda jurídica compartilhada (joint legal custody) e a guarda física compartilhada (joint physical custody). A primeira se refere à gestão colegiada da vida do infante, ou seja: "mesmo em situações de divórcio, ambos os pais possuem o direito de tomar as decisões sobre o futuro dos filhos, embora a criança resida unicamente com um dos pais, que exerce a sua guarda física" (RAMOS, 2016, p. 54).

Lado outro, a guarda física compartilhada se relaciona com a convivência, pois: "é um arranjo para que ambos os pais possam estar o maior tempo possível com seus filhos, apresentando-se sob as mais diversas modalidades, nas quais a criança fica praticamente a metade de seu tempo com cada um deles" (RAMOS, 2016, p. 54).

Com efeito, a guarda jurídica compartilhada já era reconhecida, pois a separação e o divórcio não extinguem o poder familiar. Por seu turno, a Lei n. 11.698 de 13 de junho de 2008 (Lei da Guarda Compartilhada) alterou a redação dos arts. 1.583 e 1.634 do CC/02, para instituir, expressamente, tanto a guarda jurídica compartilhada quanto a guarda física compartilhada. Posteriormente, a Lei da Guarda Compartilhada Obrigatória instituiu a obrigatoriedade da guarda física compartilhada a partir de 2014 , mesmo nos casos em que haja desacordo entre os pais, consoante art. 1.584, II, $\S 2^{\circ}$ do CC/02 (BRASIL, 2002). 
Logo, não é possível ao julgador indeferir pedido de guarda compartilhada; "sem a demonstração cabal de que um dos ex-cônjuges não está apto a exercer o poder familiar", conforme entendimento esposado pela Terceira Turma do Superior Tribunal de Justiça (STJ), no julgamento do Recurso Especial n. 1.629.994 (BRASIL, 2016).

Há crítica na doutrina acerca da obrigatoriedade da guarda compartilhada em casos de violência doméstica e familiar, considerando que as visitações podem ser usadas como instrumento de manutenção do ciclo de violência, conforme avaliado pela Comissão Permanente Mista de Combate à Violência contra a Mulher, que propôs alterações na Lei da Guarda Compartilhada Obrigatória (BRASIL, 2018).

Entretanto, a crítica em questão não inviabiliza a obrigatoriedade da guarda compartilhada, porquanto a legislação prevê causas obstativas à sua fixação como: perda do poder familiar, declaração de um dos genitores de que não deseja a guarda e circunstâncias que inviabilizam o exercício conjunto da guarda física. Nesse ponto, o STJ, no bojo do Recurso Especial n. 1.605.477, entendeu ser inviável a implementação da guarda compartilhada quando os pais morarem em cidades distintas (BRASIL, 2016).

Além disso, deve-se observar se os genitores estão aptos a cuidar do filho, de modo que, nos termos do art. 1.584 , II, $\$ 5^{\circ}$ do CC/02:

\footnotetext{
Se o juiz verificar que o filho não deve permanecer sob a guarda do pai ou da mãe, deferirá a guarda à pessoa que revele compatibilidade [...] considerados, de preferência, o grau de parentesco e as relações de afinidade e afetividade (BRASIL, 2002).
}

Outrossim, o art. 1.584, II, $\S 3^{\circ}$ do CC/02 prevê o auxílio de equipe multidisciplinar ao magistrado para estabelecer o tipo de guarda, as atribuições dos genitores e a divisão dos períodos de convivência com o filho de forma equilibrada (BRASIL, 2002).

Destarte, a sistemática traçada pela Lei da Guarda Compartilhada Obrigatória visa a operar uma mudança de paradigma no tratamento da guarda e do divórcio, porquanto, em regra, deferia-se a guarda unilateral à 
genitora, a partir do pressuposto de que a mulher deveria ser mãe antes de tudo (BADINTER, 1985).

Nesse sentido, segundo Badinter (1985), desde 1970, abundaram publicações que recomendavam à mãe cuidar pessoalmente dos filhos e lhes ordenava amamentá-los, obstando sua inserção no mercado de trabalho e a igualdade de deveres entre os pais. Contudo, esse entendimento não se harmoniza com a CF/88 e opera desarranjos que encontram ressonância nos dias atuais. Logo, o paradigma da guarda unilateral entrou em crise, indicando que: "é chegada a ocasião para renovar os instrumentos" (KUHN, 2011, p. 105). Isso porque, essencialmente, o paradigma estabelece o impasse a ser resolvido, pois: "[...] a teoria do paradigma está diretamente implicada no trabalho de concepção da aparelhagem capaz de resolver o problema" (KUHN, 2011, p. 48).

No viés instrumental, leciona Habermas (1997) que a função do direito é mediar a tensão entre facticidade e validade, pois nem sempre a abstração das normas jurídicas será capaz de se adequar efetivamente ao caso concreto, podendo dispor de forma contrária aos anseios sociais. Por conseguinte, a guarda unilateral não estava, na maioria dos casos, garantindo o exercício igualitário do poder familiar entre os genitores, nem o melhor interesse da criança, incompatibilizando a previsão legal com os fundamentos principiológicos do ordenamento e sua adequação ao caso concreto, tanto que, estatisticamente, mesmo após a instituição da obrigatoriedade da guarda compartilhada, predomina a detenção pelas mulheres da guarda dos filhos menores na ocasião do divórcio.

Em 2018, esse percentual atingiu o valor de 65,4\%, que, apesar de alto, é menor que o percentual dos anos anteriores, sendo 69,4\%, em 2017, e 74,4\%, em 2016. Desse modo, vislumbra-se que, com a crise da guarda unilateral, a obrigatoriedade da guarda compartilhada vem alcançando êxito na mudança de paradigma, pois sua adoção, entre arranjos familiares com filhos menores, passou de 7,5\%, em 2014, para 24,4\% em 2018 (IBGE, 2018). 


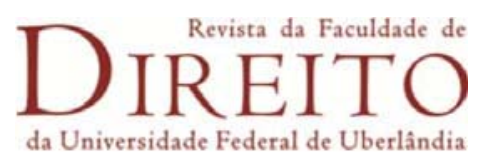

Portanto, além de garantir a convivência dos filhos com os pais, a Lei da Guarda Compartilhada Obrigatória estimula a mudança de paradigma na condução do divórcio, por meio da transcendência dos conflitos advindos do rompimento do vínculo conjugal para a busca do melhor interesse da criança.

\section{Alienação parental nos moldes da Lei no 12.318/2010}

Com a dissolução da entidade familiar, o direito de convivência dos pais com os filhos não pode restar prejudicado. Assim, quando o genitor é obstado da convivência com o infante, sem haver perda ou suspensão do poder familiar, pode se configurar situação de alienação parental, que é definida no art. $2^{\circ}$ da Lei da Alienação Parental como:

[...] a interferência na formação psicológica da criança ou do adolescente promovida ou induzida por um dos genitores, pelos avós ou pelos que tenham a criança ou adolescente sob a sua autoridade, guarda ou vigilância para que repudie genitor ou que cause prejuízo ao estabelecimento ou à manutenção de vínculos com este (BRASIL, 2010).

Esse é o processo abordado no presente artigo e não se confunde com a síndrome da alienação parental (SAP), termo cunhado pelo psiquiatra americano Richard Alan Gardner, para denominar a patologia decorrente do processo de alienação parental, que culmina com a implantação de falsas memórias no filho alienado (GARDNER, 2002). Em sede de aproximação, tanto a alienação parental, quanto a SAP se intensificam com a diminuição da convivência do filho com algum de seus genitores (GARDNER, 2002).

Não obstante, parte da doutrina desacredita da existência da SAP, haja vista que os atos de alienação, dirigidos contra o vínculo familiar, independem da existência de um complexo de sintomas atribuíveis à vítima dessa suposta condição (BRASIL, 2018). Além disso, considerável parte da doutrina, sobretudo estrangeira, sustenta a inexistência de embasamento 
científico para a classificação da síndrome da alienação parental como patologia (SOTTOMAYOR, 2011).

Nessa linha, alega-se que as medidas de afastamento da criança do suposto genitor alienante são demasiadamente severas, bem como dificultam o entendimento acerca dos motivos da mudança comportamental do infante. Há, ainda, apontamentos sobre discriminação de gênero, pois, majoritariamente a mãe detém a guarda do filho, de modo que a figura feminina se tornaria a alienadora (FERREIRA; ENZWEILER, 2014).

As discussões se intensificaram após a identificação, pela Comissão Parlamentar de Inquérito dos Maus Tratos Contra Crianças e Adolescentes (CPI dos Maus Tratos), de margem para o mau uso da lei, com a finalidade de alteração da guarda pelo genitor abusador, que ocorre da seguinte forma:

[...] genitores acusados de cometer abusos ou outras formas de violência contra os próprios filhos teriam induzido ou incitado o outro genitor a formular denúncia falsa ou precária, como subterfúgio para que seja determinada a guarda compartilhada ou a inversão da guarda em seu favor. Seria uma forma ardilosa pela qual um genitor violento manipularia o outro de modo a obter o duplo benefício de acesso à vítima e afastamento do protetor (BRASIL, 2018, p. 41).

Consequentemente, a aplicação da Lei da Alienação Parental pode acobertar abusos sexuais, em razão da possibilidade de eventual denúncia ser interpretada como prática de alienação parental (FERREIRA; ENZWEILER, 2014). Inclusive, esse cenário já foi observado em processos judiciais, conforme leciona Dias (2010, p. 1): "Nos processos envolvendo abuso sexual, a alegação de que se trata de síndrome da alienação parental tornou-se argumento de defesa e vem sendo invocada como excludente de criminalidade".

Em razão da possibilidade de mau uso da Lei de Alienação Parental e de seus institutos, o Projeto de Lei do Senado n. 498 de 2018 (PLS 498/18) propõe a revogação da Lei da Alienação Parental (BRASIL, 2018). No entanto, não se pode olvidar o escopo de referida lei de proteção de crianças e adolescentes, que sofrem diversos abusos, inclusive no âmbito emocional, 
infligido pela alienação parental, de modo que sua revogação violaria o princípio da vedação ao retrocesso social que impõe a "manutenção dos níveis gerais de proteção social alcançados no âmbito do Estado Social" (SARLET, 2009, p.436).

Além disso, apesar do temor do mau uso da lei, com a inversão indevida da guarda, é importante salientar que a alienação parental possui três estágios, e que a inversão da guarda apenas ocorre na fase severa, após extensa instrução probatória. Nesse ponto converge a doutrina acerca da necessidade de critérios rígidos e estudos aprofundados para se averiguar a efetiva ocorrência do processo alienante, o que já é previsto na Lei de Alienação Parental (FERREIRA; ENZWEILER, 2014).

Acerca das fases da alienação, verifica-se no estágio inicial ou leve a campanha de difamação; mas existe ainda sentimento de afeto para com o outro genitor. Nessa hipótese, deve se assegurar a mínima visitação assistida, salvo casos de iminente risco de prejuízo físico ou psicológico do infante, atestado por profissional a ser designado pelo juiz, conforme dispõe o art. $4^{\circ}$, parágrafo único da Lei da Alienação Parental (BRASIL, 2010).

Já na alienação parental classificada como moderada, aparecem os primeiros sinais de dicotomia; em que um genitor é bom e o outro é mau. Isso porque o motivo das agressões se torna consciente e reúne os sentimentos e desejo da criança e do genitor alienante, criando uma cumplicidade entre alienador e filho (MADALENO, 2013). Nesse estágio, preceitua o art. $5^{\circ}$ da Lei da Alienação Parental, que o juiz determinará perícia psicológica ou biopsicossocial, com prazo de noventa dias para apresentação de laudo, passível de prorrogação a critério do juiz e em decisão fundamentada (BRASIL, 2010).

Por fim, nos casos severos, o infante se encontra extremamente perturbado e as visitas são muito difíceis, ou sequer ocorrem. O vínculo entre filho e genitor alienado é rompido. Nessa fase, entre outras medidas, o 
magistrado pode determinar a alteração da guarda para a modalidade compartilhada, ou sua inversão (MADALENO, 2013).

Importante, ainda, distinguir a alienação parental da alienação autoinfligida ou autoalienação, em que o próprio genitor alienado provoca o afastamento da criança ou adolescente não por desamor; mas por medo, tendo em vista o tratamento ríspido, cruel e desumano que lhe é dispensado. Consequentemente, acusa o outro genitor de alienação parental; porém, não faz jus às medidas previstas na lei, por não restar configurada referida prática (MADALENO, 2013).

No âmbito processual, a alienação parental pode ser reconhecida, a qualquer tempo, de ofício pelo magistrado, por provocação do Ministério Público ou da parte interessada. Ao tomar o depoimento do infante, quando a discussão de fato envolver alienação parental, o juiz deve ser acompanhado por especialista (TARTUCE, 2018).

$\mathrm{O}$ art. $2^{\circ}$, parágrafo único da Lei da Alienação Parental prevê, ainda, rol exemplificativo de condutas que possam configurar a prática, como realização de campanha de desqualificação da conduta do genitor e obstaculização do exercício da autoridade parental, de modo que a alienação parental viola o direito de convivência, a dignidade do infante e do parente vitimado, pois: “[...] ao acarretar o afastamento da criança com seus parentes, cria buracos nas relações afetivas que dificilmente conseguem ser restabelecidos" (FIGUEIREDO; ALEXANDRIDIS, 2014, p. 60). Ademais, a alienação parental constitui abuso moral contra a criança e descumprimento dos deveres inerentes à autoridade parental ou decorrentes de tutela ou guarda. Em razão disso, pode acarretar, conforme arts. $6^{\circ}$ e $7^{\circ}$ da Lei de Alienação Parental, a perda da guarda, a remoção da pessoa do tutor ou curador, ou à suspensão da autoridade parental (TARTUCE, 2018).

Outrossim, o magistrado pode, dentre outras medidas: declarar a ocorrência da alienação parental e advertir e/ou estipular multa ao alienador; ampliar o regime de convivência familiar em favor do genitor 
alienado; determinar acompanhamento psicológico e/ou biopsicossocial; bem como a fixar cautelarmente do domicílio do infante (BRASIL, 2010).

No que tange à guarda, há preferência pela modalidade compartilhada, como medida repressiva da alienação parental, ou, no caso de impossibilidade, é possível atribuir a guarda unilateral: “[...] ao genitor que viabiliza a efetiva convivência da criança ou adolescente com o outro genitor" (BRASIL, 2010). Portanto, percebe-se que o ordenamento brasileiro vem criando mecanismos para dirimir e prevenir distúrbios como a alienação parental, tendo em vista a dignidade da pessoa humana e a estabilidade das entidades familiares, mesmo com o fim do matrimônio.

\section{Efetividade da guarda compartilhada obrigatória como prevenção à alienação parental}

A guarda compartilhada, além de atuar como medida repressiva à alienação parental, coopera com a convivência familiar mais harmônica, em consonância com o princípio da isonomia. Nessa linha:

\footnotetext{
A previsão legislativa da guarda compartilhada reforça a importância da participação de ambos os pais na vida de seus filhos. Antes de qualquer efeito jurídico, já tem um impacto na mente dos pais envolvidos que evita o sentimento de perda, natural em processos judiciais, quando a guarda do filho é concedida ao outro (RAMOS, 2016, p. 67).
}

Segundo Dias (2011), a guarda compartilhada empreendeu uma mudança significativa de costumes, ensejando a participação de ambos os pais na vida dos filhos. Além disso, essa modalidade busca o exercício recíproco de direitos e deveres dos genitores para com os filhos comuns, com fortalecimento do poder familiar e intervenção estatal para redução de litígios, o que possibilita a separação entre os conflitos advindos da conjugalidade desfeita do exercício da parentalidade.

Portanto, a guarda compartilhada obrigatória se demonstra eficaz como prevenção da alienação parental, tanto pela sua sistemática de 
compartilhamento de obrigações, quanto por seus fundamentos, que englobam diálogo e apoio de equipe multiprofissional. Desse modo:

A intervenção de uma equipe interdisciplinar [...] faz-se [...] necessária, seja antes ou após a intervenção de um mediador, na hipótese de resistência de um dos pais, possibilitando que os arranjos atendam aos interesses da família [...], garantindo ao infante o seu bem-estar e o direito à convivência familiar (RAMOS, 2016, p. 72).

Logo, o estímulo ao diálogo auxilia o consenso entre os genitores, visando à proteção do melhor interesse da criança, sobretudo quando guiado estrategicamente, sendo possível alcançar a solução autocompositiva dos conflitos, que se opera pelas próprias partes, seja por meio da mediação ou da conciliação (MUSZKAT, 2003). Há, contudo, entendimento acerca da impossibilidade de aplicação de mecanismos extrajudiciais de solução de conflitos aos casos que versam sobre alienação parental, o que motivou, inclusive, o veto ao art. $9^{\circ}$ da Lei da Alienação Parental (BRASIL, 2010).

Não obstante, observa-se, pela interpretação sistemática, que a mediação é aplicável aos casos de alienação parental, porquanto não se trata de disposição de direito; mas de viabilização do diálogo em prol do melhor interesse da criança. Ademais, ela pode ser efetuada no bojo do processo judicial, conforme orientação dos arts. 165 e 694 do CPC/15, não havendo violação ao interesse público (BRASIL, 2015).

Nesse ponto, o Projeto de Lei do Senado n. 144/2017 (PLS 144/2017), já aprovado nessa casa e remetido à Câmara dos Deputados (PL 6008/2019), prevê a aplicabilidade da mediação à Lei da Alienação Parental. Conceitualmente, nos termos do art. $1^{\circ}$, parágrafo único da Lei n. 13.140 de 26 de junho de 2015 (Lei de Mediação), a mediação é: "a atividade técnica exercida por terceiro imparcial sem poder decisório, que, escolhido ou aceito pelas partes, as auxilia e estimula a identificar ou desenvolver soluções consensuais para a controvérsia" (BRASIL, 2015). Diversamente, na conciliação, há a presença de terceiro imparcial que é catalizador da transação, promovendo solução mais rápida ao litígio (BRASIL, 2015). 
Para conflitos na seara familiar, a modalidade mais adequada é a mediação, pois objetiva alcançar o cerne do conflito pelas partes, sem limitação temporal. Para isso, estimula-se o diálogo, que é o caminho para a pacificação social (ROSENBERG, 2006).

Por conseguinte, exige-se, junto à mudança de paradigma promovida pela obrigatoriedade da guarda compartilhada, a migração para a comunicação não violenta, que consiste em observar as situações sem julgamentos, identificar os sentimentos que surgem com aquelas ações, reconhecer as necessidades atreladas àqueles sentimentos e o que se quer pedir ou expressar. Deve-se também receber com empatia as palavras, construindo um diálogo de compreensão mútua (ROSENBERG, 2006).

No âmbito psíquico, a guarda compartilhada enseja o acompanhamento psicológico ou psiquiátrico, conforme prevê o $\mathrm{CPC} / 15$ e o art. 129, III, do ECA, tendo em vista a importância do cuidado com emoções, angústias, traumas e anseios comuns a um contexto de ruptura conjugal (BRASIL, 1990). A mudança de paradigma no tratamento do divórcio e da guarda desencadeada pela guarda compartilhada obrigatória, associada à mediação e ao acompanhamento multiprofissional, enseja a prevenção da alienação parental, pois reduz os pontos de conflito advindos da separação, por meio da comunicação não violenta.

Há, portanto, uma fluidez no entendimento e no diálogo, com respeito entre os genitores, o que agrega ao bem estar da criança e do adolescente. Associa-se a essa sistemática a conscientização dos pais acerca do funcionamento da guarda compartilhada.

Nessa linha, a Recomendação no 32 do Conselho Nacional do Ministério Público cita a guarda compartilhada obrigatória e destaca a necessidade de conscientização da sociedade e daqueles que trabalham no meio jurídico, por meio de palestras, com maior atenção aos direitos das crianças e adolescentes, e ações afirmativas para efetivação dos vínculos familiares e parentais (CNMP, 2016). Ademais, o Conselho Nacional de 
Justiça (CNJ) oferece a Oficina de Pais e Mães, que visa a auxiliar famílias que enfrentam conflitos de separação através de oficinas online. Procura, ainda, preservar uma relação saudável do casal junto aos filhos, permitindo a adaptação à nova realidade.

No âmbito privado, com o mesmo objetivo, há organizações nacionais e internacionais que promovem a criação de grupos de apoio familiar, como a Associação Pais Para Sempre (APPS), em Portugal, e a Associação de Pais e Mães Separados (APASE), no Brasil (DIAS, 2011). Portanto, verifica-se que a instituição da obrigatoriedade da guarda compartilhada inaugurou nova tratativa do processo de divórcio e guarda dos filhos no país, pois estabeleceu sistemática multidisciplinar de enfrentamento aos problemas que dele decorrem, tratando-se de meio efetivo de prevenção da alienação parental.

\section{Conclusão}

Do presente trabalho, depreende-se que o conceito de família se modificou ao longo do tempo, de acordo com os valores de cada sociedade. Pela análise da gradação histórica, verifica-se o aumento da proteção de crianças e adolescentes. Nesse sentido, a CF/88 prevê a doutrina da proteção integral e dispõe acerca do exercício do poder familiar de forma equânime entre os genitores, em consonância com os princípios do melhor interesse da criança, da prioridade, do cuidado e da afetividade.

Portanto, atualmente, o conceito de família se fundamenta nos laços afetivos, o que ocasionou a despatrimonialização dessa seara, devendo o casamento e a união estável se pautar na comunhão de vida. Inexistindo esse requisito, a união não subsiste, facilitando a EC 66/2010 a dissolução das entidades familiares. No entanto, o que não se separa são os filhos, porquanto possuem o direito fundamental de conviver com os pais, podendo a guarda ser uma alternativa para garanti-lo. 
Nessa toada, em alguns casos, a fixação da guarda unilateral potencializava os litígios entre os genitores. Em razão disso, e pela incompatibilidade com os valores constitucionais da dignidade e da proteção integral, o paradigma da guarda unilateral entrou em crise.

Concomitantemente, a regulamentação da alienação parental revelou a existência de abuso emocional, violador do direito à convivência, que antes passava despercebido, de modo que sua revogação iria de encontro ao princípio da vedação ao retrocesso. Não obstante, diante da complexidade do instituto em questão, não se descarta a possibilidade de aperfeiçoamento da lei.

Lado outro, quanto ao problema a ser respondido pela presente pesquisa acerca da efetividade da guarda compartilhada obrigatória como prevenção da alienação parental, verifica-se que a instituição da obrigatoriedade dessa modalidade de guarda modificou a abordagem do problema, por meio do diálogo e do acompanhamento multiprofissional. Consequentemente, a guarda compartilhada se constitui como instrumento repressivo e preventivo da alienação parental, pois obsta a interferência dos litígios emergentes do rompimento do vínculo conjugal na convivência entre pais e filhos, por meio da sua resolução dialogada. Prioriza-se, assim, os interesses de crianças e adolescentes.

Portanto, conclui-se que a guarda compartilhada obrigatória é eficaz na prevenção da alienação parental, pois se fundamenta no melhor interesse da criança, viabilizando o diálogo e o respeito entre genitores, de forma a garantir o direito fundamental de convivência familiar de crianças e adolescentes.

\section{Referências}

ALEXY, Robert. Teoria dos Direitos Fundamentais. (Título original: Theorie der Grundrechte. Tradução de Virgílio Afonso da Silva). $5^{\mathrm{a}}$ ed. São Paulo (SP): Malheiros Editores, 2008. 


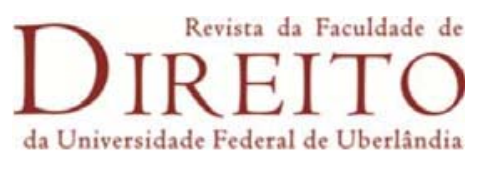

ARIÈS, Philippe. História Social da Criança e da Família. (Título Orignal: L’Enfant et la Vie familiale sous l'Ancien Régime. Tradução: Dora Flaksman). $2^{\mathrm{a}}$ ed. Rio de Janeiro (RJ): Guanabara, 1986.

BADINTER, Elizabeth. Um Amor Conquistado: O Mito do Amor Materno. (Título original: L'Amour En Plus. Tradução: Waltensir Dutra). Rio de Janeiro (RJ): Editora Nova Fronteira. $1985 . \quad$ Disponível em: $<$ http://www.redeblh.fiocruz.br/media/livrodigital\%20(pdf)\%20(rev).pdf) $>$. Acesso em 24 mai. 2015.

BARBOSA, Rui. Oração aos Moços. (Edição popular anotada por Adriano da Gama Kury). $5^{a}$ ed. Rio de Janeiro (RJ): Fundação Casa Rui Barbosa, 1999.

BOFF, Leonardo. Saber Cuidar: Ética e compaixão pela terra. Petrópolis (RJ): Vozes, 1999. BRASIL, Constituição (1988). Constituição da República Federativa do Brasil de 1988. Brasília (DF)..

BRASIL, Decreto n. 99.710 de 21 de novembro de 1990. Convenção sobre os Direitos das Crianças. Brasília (DF).

BRASIL. Lei no 10.406 de 10 de janeiro de 2002. Código Civil Brasileiro. Brasília (DF). BRASIL. Lei no 13.105 de 16 de março de 2015. Código de Processo Civil. Brasília (DF). BRASIL. Lei no 8.069 de 13 de julho de 1990. Estatuto da Criança e do Adolescente. Brasília (DF).

BRASIL, Lei n ${ }^{\circ}$ 6.515, de 26 de dezembro de 1977. Lei do Divórcio. Brasília (DF).

BRASIL, Lei $\mathrm{n}^{\circ} 13.058$ de 22 de dezembro de 2014. Lei da Guarda Compartilhada Obrigatória. Brasília (DF).

BRASIL, Lei 13.140 de 26 de junho de 2015. Lei de Mediação. Brasília (DF).

BRASIL, Câmara dos Deputados. Projeto de Lei n. 6.008 de 18 de novembro de 2019. Brasília (DF). Disponível em: $<$ https://www.camara.leg.br/proposicoesWeb/fichadetramitacao?idProposicao=2229712>

Acesso em 13 jun. 2020.

BRASIL, Câmara dos Deputados. Audiência pública da Comissão Permanente Mista de Combate à Violência contra a Mulher. Brasília (DF), 2018. Disponível em: $<$ https://www.camara.leg.br/noticias/537776-debatedoras-defendem-excecoes-a-guardacompartilhada-em-casos-de-violencia/> Acesso em 15 set. 2020.

BRASIL, Senado Federal. Projeto de Lei do Senado n. 144 de 9 de maio de 2017. Brasília (DF). Disponível em: <https://www25.senado.leg.br/web/atividade/materias/Imateria/129146> Acesso em 13 jun. 2020.

BRASIL, Senado Federal. Projeto de Lei do Senado n. 498 de 2018. Brasília (DF). Disponível em: <https://legis.senado.leg.br/sdleggetter/documento?dm=7893728\&ts $=1594018351598 \&$ disposition=inline $>$ Acesso em 9 ago. 2020.

BRASIL, Senado Federal. Relatório da Comissão Parlamentar de Inquérito dos Maus Tratos. Brasília (DF), 2018. Disponível em: $<$ https://legis.senado.leg.br/comissoes/mnas?codcol=2102\&tp=4 > Acesso em 9 ago. 2020.

BRASIL. Superior Tribunal de Justiça (Terceira Turma). Recurso Especial n. 1605477RS. Relator: Ministro Ricardo Villas Bôas Cueva, 2016. Disponível em: $<$ http://www.stj.jus.br/SCON/jurisprudencia/toc.jsp?livre=GUARDA+COMPARTILHADA+L IMITES+GEOGR\%C1FICOS\&\&tipo_visualizacao=RESUMO\&b=ACOR\&thesaurus=JURID ICO\&p=true $>$ Acesso em 22 jan. 2018.

BRASIL. Superior Tribunal de Justiça (Terceira Turma). Recurso Especial n. 1629994RJ. Relatora: Ministra Nancy Andrighi, 2016. Disponível em: 


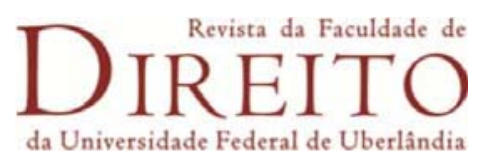

$<$ http://www.stj.jus.br/SCON/jurisprudencia/doc.jsp?livre=GUARDA+COMPARTILHADA+ POSSIBILIDADES\&b=ACOR\&p=true\&t=JURIDICO\&l=10\&i=3> Acesso em 22 jan. 2018.

BULOS, Uaidi Lammêgo. Curso de Direito Constitucional. $8^{a}$ ed. São Paulo (SP): Saraiva, 2014.

CAHALI, Yussef Said. Divórcio e Separação. $11^{\text {a }}$ ed. São Paulo (SP): Revista dos Tribunais, 2005.

CNMP, Conselho Nacional do Ministério Público. Recomendação no 32 . Brasília (DF). Disponível em: <https://www.cnmp.mp.br/portal/images/Normas/Recomendacoes/RecomendaCAO_32.pdf $>$ Acesso em: 15 mai. 2016.

COUlanges, Fustel de. A Cidade Antiga. (Título original: La Cité Antique - Étude sur Le Culte, Le Droit, Les Institutions de la Grèce et de Rome.Tradução: Frederico Ozanam Pessoa de Barros). Disponível em $<$ http://bibliotecadigital.puc-campinas.edu.br/services/ebooks/Fustel\%20de\%20Coulanges-1.pdf>. Acesso em 20 mai. 2015.

DIAS, Maria Berenice. Manual de Direito das Famílias. $7^{a}$ ed. São Paulo (SP): Editora Revista dos Tribunais, 2011.

DIAS, Maria Berenice. Incesto e a Síndrome da Alienação Parental. Porto Alegre, $2010 . \quad$ Disponível em:

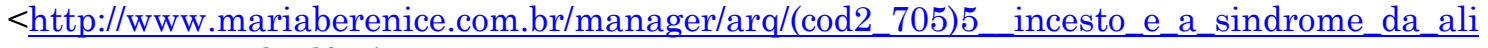
enacao_parental.pdf $>$ Acesso em 15 set. 2020.

ENGELS, Friedrich. A Origem da Família, da Propriedade Privada e do Estado. (Título original: Der Ursprung der Familie, des Privateigentaums und des Staats. Tradução: Leandro Konder). $9^{a}$ ed. Rio de Janeiro (RJ): Civilização Brasileira, 1984.

FACHIN, Luiz Edson. Direito Civil: sentidos, transformações e fim. Rio de Janeiro (RJ): Renovar, 2015.

FERREIRA, Cláudia Galiberne; ENZWEILER, Romano José. Síndrome da alienação parental, uma iníqua falácia. Revista da ESMESC, Santa Catarina, vol. 21, n.27, p.81$126,2014$.

FIGUEIREDO, Fábio Vieira; ALEXANDRIDIS, Georgios. Alienação Parental. $2^{a}$ ed. São Paulo (SP): Saraiva, 2014.

GARDNER, Richard Alan. O DSM-IV tem equivalente para o diagnóstico de Síndrome de Alienação Parental (SAP)? (Tradução: Rita Rafaeli), 2002. Disponível em: $<$ https://sites.google.com/site/alienacaoparental/textos-sobre-sap-1/o-dsm-iv-temequivalente>Acesso em 14 jun. 2020.

FRANÇA, Declaração de Direitos. Declaração dos Direitos do Homem e do Cidadão. (Título original: Declaration des Droits de l'Homme et du Citoyen. Tradução: Marcus Cláudio Acqua Viva). São Paulo: Saraiva, 1798.

HABERMAS, Jürgen. Direito e Democracia: entre facticidade e validade. 2 ed. vol. 1 (Tradução: Flávio Beno Siebeneichler). Rio de Janeiro (RJ): Tempo Brasileiro, 1997.

HEIDEGGER, Martin. Ser e Tempo: parte I. $15^{\text {a }}$ ed. Rio de Janeiro (RJ): Vozes, 1986.

IBGE, Instituto Brasileiro de Geografia e Estatística. Estatísticas do Registro Civil de $1984 . \quad$ Disponível em: $<$ https://biblioteca.ibge.gov.br/visualizacao/periodicos/135/rc_1984_v11.pdf > Acesso em 16 mar. 2018.

IBGE, Instituto Brasileiro de Geografia e Estatística. Estatísticas do Registro Civil de $2018 . \quad$ Disponível em: <https://biblioteca.ibge.gov.br/visualizacao/periodicos/135/rc_2018_v45_informativo.pdf>

Acesso em 11 jun. 2020. 


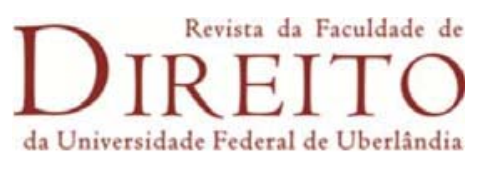

KANT, Immanuel. Fundamentação da Metafísica dos Costumes. (Título original: Grundlegungzur Metaphysic der Sitten. Tradução: Paulo Quintela). Lisboa: Edições 70, 2007.

KUHN, Thomas S., A Estrutura das Revoluções Científicas. (Título original: The Structure of Scientific Revolutions. Tradução: Beatriz Vianna Boeira e Nelson Boeira). 10 ed. São Paulo (SP): Perspectiva, 2011.

MADALENO, Rolf. Curso de Direito de Família. $5^{\text {a }}$ ed. Rio de Janeiro (RJ): Forense, 2013.

MIRANDA, Pontes de. Tratado de Direito de Família: Direito Matrimonial. vol. 1. Campinas (SP): Bookseller, 2001.

MUSZKAT, Malvina Ester. Mediação de Conflitos: Pacificando e prevenindo a violência. São Paulo (SP): Summus Editorial Ltda., 2003.

PEREIRA, Caio Mário da Silva. Instituições de Direito Civil: Direito de família. $26^{a}$ ed. vol. 5. Rio de Janeiro (RJ): Forense, 2018.

PERLINGIERI, Pietro. Perfis do Direito Civil. Rio de Janeiro (RJ): Renovar, 1997.

PIOVESAN, Flávia. Direitos Humanos e o Direito Constitucional Internacional. $14^{\mathrm{a}}$ ed. São Paulo (SP): Saraiva, 2013.

RAMOS, Patrícia Pimentel de Oliveira Chambers. Poder Familiar e Guarda Compartilhada: novos paradigmas do direito de família. $2^{a}$ ed. São Paulo (SP): Saraiva, 2016.

RIBEIRO, Paulo Hermano Soares; SANTOS, Vivian Cristina Maria; SOUZA, Ionete de Magalhães. Nova Lei de Adoção Comentada. $2^{a}$ ed. São Paulo (SP): JH Mizuno, 2012.

ROSENBERG, Marshall B. Comunicação Não Violenta: Técnicas Para Aprimorar Relacionamentos Pessoais e Profissionais. (Título original: Nonviolent Communication: a language of life. Tradução: Mário Vilela). $2^{a}$ ed. São Paulo (SP): Ágora, 2006.

SARLET, Ingo Wolfgang. A Eficácia dos Direitos Fundamentais: uma teoria geral dos direitos fundamentais na perspectiva constitucional. 10 a ed. Porto Alegre (RS): Livraria do Advogado, 2009.

SOTTOMAYOR, Maria Clara. A fraude da síndrome de alienação parental e a proteção das crianças vítimas de abuso sexual. In Conferência Internacional "O superior interesse da criança e o mito da "Síndrome da Alienação Parental", no painel "A Síndrome da Alienação Parental e os riscos para os direitos das mulheres 58 e das crianças", 2011. Disponível em: <http://www.eas.pt/wpcontent/uploads/2014/01/A-fraude-da-SAP-e-aprotec\%C3\%A7_o-dascrian\%C3\%A7as-v\%C3\%ADtimas-de-abuso-sexual.pdf>. Acesso em: 15 set. 2020.

TARTUCE, Fernanda. Processo Civil no Direito de Família: Teoria e Prática. $3^{\text {a }}$ ed. São Paulo: Método, 2018.

VENOSA, Sílvio de Salvo. Direito Civil: Família. 17 ed. vol. 5. São Paulo (SP): Atlas, 2017.

Artigo recebido em: 22/06/2020.

Aceito para publicação em: 20/04/2021. 